\title{
A Cross-Cultural Study of Offering Advice Speech Acts by Iranian EFL Learners and English Native Speakers: Pragmatic Transfer in Focus
}

\author{
Sherveh Babaie ${ }^{1} \&$ Mohsen Shahrokhi ${ }^{1}$ \\ ${ }^{1}$ Department of English, Shahreza Branch, Islamic Azad University, Shahreza, Isfahan, Iran \\ Correspondence: Mohsen Shahrokhi (Ph.D.), Department of English, Shahreza Branch, Islamic Azad University, \\ Shahreza, Isfahan, Iran. Tel: 98-31-5350-2501. E-mail: shahrokhi1651@yahoo.com
}

Received: February 27, 2015 Accepted: March 29, 2015 Online Published: May 28, 2015

doi:10.5539/elt.v8n6p133 URL: http://dx.doi.org/10.5539/elt.v8n6p133

\begin{abstract}
The purpose of the present study was to compare the speech act of offering advice as realized by Iranian EFL learners and English native speakers. The study, more specifically, attempted to find out whether there was any pragmatic transfer from Persian (L1) among Iranian EFL learners while offering advice in English. It also examined whether Iranian EFL learners' perception of directness/indirectness in the realization of offering advice develops as a result of proficiency development. In order to achieve the objectives, a Discourse Completion Test (DCT) was used to collect the speech act of offering advice from among Iranian EFL learners and native English speakers. The findings indicated that Iranian EFL learners were not as balanced as native English speakers in the use of indirect use of offering advice. It was also observed that Iranian EFL learners had not acquired the pragmatic competence to offer native-like advice with regard to social power and social distance between interlocutors. The result also revealed that Iranian EFL learners and the native English speakers favored a number of similar strategies for the realization of offering advice, though there were differences in terms of frequency use of the speech acts of offering advice. Thus, this study showed evidence of pragmatics transfer.
\end{abstract}

Keywords: Iranian EFL learners, cross-cultural studies, pragmatics, offering advice, transfer, directness

\section{Introduction}

\subsection{Background to the Study}

Throughout the English language teaching history, the successful language use has been regarded as an important principle and the use of Communicative Language Teaching (CLT) was an attempt to foster the successful language use (Hymes, 1971). Thus, the accuracy of language use has gained momentum in second language acquisition. When Hymes (1971) proposed the concept of "communicative competence", i.e., the speaker's knowledge of both linguistic and socio-cultural rules in spoken language, the style of both second language teaching and learning underwent a change of focus from grammatical competence to communicative competence.

According to Hymes' theory, the aim of language instruction is to teach learners not only to use language accurately but also to use it appropriately. There are four types of knowledge including feasibility, attest ability, possibility as well as appropriateness, which are all integral parts of communicative competence. Therefore, pragmatic competence, which has been defined as "the speaker's knowledge and use of rules of appropriateness and politeness, which dictate the way the speaker will understand and formulate speech acts" (Koike, 1989, p. 279), makes an essential component of Hymes' conceptual model. Undeniably, language learners who wish to become communicatively competent, not only need to have knowledge of lexicon and grammar, which are "important...but not sufficient" (Olshtain \& Cohen, 1991, p. 154), but also to acquire knowledge of "the social and contextual factors underlying the English language" (Uso-Juan \& Martinez-Flor, 2008, p. 349); the knowledge is of great significance in inter-cultural communication (White, 1993).

Research into the field of second language acquisition (SLA) indicated that the learners' native language plays an influential role in learning a second/foreign language. In this regard both positive transfer (facilitation) and negative transfer (interference) may play a role. According to Kasper (1992), two types of negative pragmatic transfer (pragmatic linguistic transfer and socio-pragmatic transfer) might interfere with communication. The negative pragmatic linguistic transfer is taken into account as the influences of first language pragmatics on 
language learners' inter-language pragmatic forms and functions. The negative pragmatic transfer can result in the use of forms and functions in the learners' second/foreign language (called also inter-language) which might be different from those used by the native speakers of the target language. "The negative socio-pragmatic transfer, on the other hands, occurs when second language learners assume second language contexts in the same way as first language context and reflect their perceptions from a specific situation in first language to second language situation" (Kasper, 1992; as cited in Chang, 2008, p. 2).

Thus, the relationship between pragmatics and the area of SLA makes a new field known as inter-language pragmatics (ILP). Kasper (1992, p. 203), defined inter-language pragmatics as "the branch of second language research which studies how non-native speakers [...] understand and carry out linguistic action in a target language, and how they acquire second language pragmatic knowledge". Inter-language pragmatics has provided a spring board for investigation in recent decades. A majority of the research had been carried out to analyze learners in second language settings (Olshtain \& Blum-Kalka, 1985; Takahashi \& Dufon, 1989; Koike, 1996; Hassall, 1997, to provide few examples). Furthermore, different pragmatic components, such as discourse markers, interactional routines, implicatures, or speech acts such as compliments, requests, refusals, complaints, and apologies have been tackled in ILP research studies (e.g., Eslamirasekh, 1993; Hassall, 2003; Shahrokhi, 2012; Shahrokhi \& Jariah, 2012, to name few studies).

Research showed that while speech acts themselves are universal, the socio-pragmatic rules or norms governing the appropriate representation of any certain speech act differ greatly between cultures and languages (e.g., see Matsumura, 2001 on advice; Golato, 2002; Nelson et al., 1996 on compliments; Blum-Kulka, House, \& Kasper, 1989; Cohen \& Olshtain, 1993 on requests; DeCapua, 1998; Boxer, 1993 on complaints; Eisenstein \& Bodman, 1993 on expressions of gratitude; Beebe \& Takahashi, 1989; Fe'lix-Brasdefer, 2004; Gass \& Houck, 1999; Kwon, 2004 on refusals). When non-native speakers transfer their mother tongue socio-pragmatic norms into the target language, or are merely unaware of the various socio-pragmatic rules, this situation often results in cross-cultural misunderstandings and misattribution of intent (e.g., Bardovi-Harlig \& Do"rnyei, 1998; DeCapua, 1998; DeCapua \& Wintergerst, 2004; Kasper, 1998; Kotani, 2002; Olshtain \& Kulka, 1985; Qin, 2003).

Furthermore, the speech act theory introduced by Austin (1962) and Searle (1975) prompted many studies in inter-language pragmatics. Cross-cultural communication and pragmatic transfer have laid themselves open to critical investigation in order to promote cross-cultural understanding in the field of SLA. It also produced some information in order to facilitate language instruction and language acquisition. Therefore, language pedagogy should improve language learners' pragmatic competence and awareness in their target language, by emphasizing on one of the important pragmatic features, namely speech acts, through adequate pedagogical instructions and practices. ILP, which is necessary in both language learning and teaching, is associated with non-native speakers' comprehension and production of pragmatics and how that second language-related knowledge is learned.

The main impetus that motivated the researchers of the current study to conduct the study was to check whether Iranian EFL learners' pragmatics competence develops enough as proficiency level develops to enable them to communicative as native English speakers communicate as far as the realization of the speech act of offering advice is concerned. Therefore, the current pragmatics study attempted to compare Iranian EFL learners' realization of offering advice speech act with those of native English speakers. Since pragmatic transfer in offering advice by Iranian learners of English may bring about breakdowns in their inter-cultural communication, the issue needs to be addressed in order to know how Iranian EFL learners' first language pragmatic competence may influence their performance in offering advice in English. The study also examined whether Iranian EFL learners' perception of directness/indirectness in the realization of offering advice develops as a result of proficiency development.

\subsection{Research Questions}

Based on the objectives explained above the following research questions were posed to be sought.

RQ1: To what extent the realization of offering advice speech act is different between Iranian EFL learners (Low, mid, and high proficiency levels) and native English speakers in terms of frequency use and type?

RQ2: To what extent the perception of directness is different between Iranian EFL learners (Low, mid, and high proficiency levels) and native English speakers in the realization of offering advice speech act?

\section{Method}

The current cross-cultural research was conducted based on a descriptive design. The study involved both Iranian EFL learners and native English speakers. Both qualitative and quantitative data collection and data analysis 
procedures were employed in the study as explained in the following sections.

\subsection{Participants}

A number of 82 Iranian EFL learners who were both BA and MA students and aged between 22 to 46 were selected from Islamic Azad University, Shahreza, Iran. The study used the purposive sampling to select the participants. Therefore, the prospective participants were expected to "possess certain key characteristics that are related to the purpose of the investigation" (Dörnyei, 2007, p. 99).

They were divided into three groups based on Oxford Placement Test: 19 participants were at low level, 37 participants at mid-level, and 26 participants at high level English proficiency.

In addition to Iranian EFL learners, a group of 20 native speakers of English who aged between 19 to 50 with different academic backgrounds and professional experiences participated in the study. The native English speakers' consents were obtained by a research assistant who was living in England and was a relative of one of the authors. The native English speakers who were studying and living in England participated in the study via E-mail. It is worth mentioning that since age was not the concern of this study, there was no age-limit set for the participants of the study.

\subsection{Instruments and Data}

First, the Oxford Placement Test (OPT) was administrated to 82 selected Iranian EFL learners to determine their English language proficiency levels. Based on the results obtained through the OPT, they were divided into three groups according to their proficiency levels: low (19 learners), mid (37 learners) and high (26 learners). Then, a Discourse Completion Task (DCT) questionnaire which was adapted from Hinkle's (1997) was employed to collect the data. Participants were given instructions on how to answer the questions. No time constraint was set for answering the questions in order for the participants to answer the questions carefully and patiently. In other words, the situations were explained and the participants were required to write down their verbal reactions in those situations and responded as they utter the statements in real world conversations. The questionnaire included 24 situations. The situations were designed based on the situations in Hinkle's study (1997). In order to make the situations more culturally appropriate minor modifications were made in the original situations. Therefore, in this study, the researchers consulted a few EFL professors and native English speakers to obtain the confirmatory validity of the DCT and to make sure the revised situations were feasible enough in daily lives. Based on the feedbacks collected, some situations were further modified in order to provide cultural equivalence. The situations led to the elicitation of offering advice from among the participants of the study. The researchers were in contact via E-mail with the research assistant who distributed and collected the DCT questionnaire from among native English speakers.

\subsection{Data Analysis}

The Cross Cultural Speech Act Realization Project (CCSARP) classification was used to analyze and categorize the data collected from among the participants of the study. After its development by Blum-Kulka et al. (1989), the CCSARP has been used in many studies and has been reported as a reliable and valid data collection instrument (e.g., Lwanga-Lumu, 2002; Wouk, 2006). The CCSARP schematized offering advice strategies in three different categories: directness level, internal modification, and external modification.

One of the concerns of the current research was the evaluation of directness in offering advice strategies as realized by the participants of the study. Following Blum-Kulka et al. (1989) three levels of directness for the realization of offering advice speech act were selected. The three levels included direct offering advice, conventionally indirect offering advice, and non-conventionally indirect offering advice. Based on the scale of CCSARP, the directness of advice strategies were identified with regard to the extent a particular advice strategy head act was direct or indirect.

A detailed description of the strategies employed at different levels of directness for offering advice is as follows:

\subsubsection{Direct Offering Advice}

This level included the following strategies

Mood Derivable: in this strategy the mood of the verb signals as a command. For instance, stop smoking because smoking is bad for the health;

Performative: in this strategy the illocutionary force is explicitly named. For example, I am asking you to stop smoking because...; 
Hedging expressions: For instance, I would like to ask you to stop smoking because...;

Obligation Statement: An utterance that states the obligation of the hearer to carry out the act. Such as you will have to stop smoking because...;

Want Statement: An utterance that states the speaker's desire that the hearer carry out the act. For instance, $I$ really want you to stop smoking because smoking is really bad for the health.

\subsubsection{Conventionally Indirect Offering}

This level was instantiated through the following strategies:

Suggestory Formula: An utterance that contains a suggestion to do something, such as How about stopping smoking? I heart that smoking is really bad for health,

Preparatory Condition: An utterance that has a reference to preparatory conditions. For instance, Could you stop smoking?

\subsubsection{Non-Conventionally Indirect Offering Advice}

This level consisted of the strategies exemplified below:

Strong Hint: This type of utterance consists of partial reference to an object or element which is required for implementation of the act. For example, you are seriously damaging your lungs and thus reducing your life span each time you smoke.

Mild Hint: An utterance that makes no reference to the advice proper but can be interpreted as advice by context for example, be like the pope. (The pope doesn't smoke.)

Only the head acts, which were classified based on the nine levels of directness, were regarded for further analysis. The statistical analysis was conducted by using SPSS 16.0. The frequency analysis was conducted in order to calculate the frequency use and the percentage of offering advice strategies applied by Iranian EFL learners and native English speakers. Then, the data were categorized into three main levels of directness, namely direct, conventionally indirect, and non-conventional indirect. Furthermore, the frequency use of these three main categories of offering advice strategies was determined. In order to check whether the differences in the frequency of strategies realized by the participants were statistically significant the Chi square statistical procedure was applied.

\section{Findings}

The primary analysis of the data led to the formation of categorization and frequency use of the offering advice speech act as realized by both Iranian EFL learners and native English speakers. Table 1 displays the descriptive statistics of the findings of data analysis.

Table 1. Frequency and percentage of offering advice by native English speakers and Iranian EFL learners

\begin{tabular}{llllll}
\hline \multirow{2}{*}{ Directness Level } & Strategy & Native-E & Low & Mid & High \\
& & F (\%) & F (\%) & F (\%) & F (\%) \\
\hline \multirow{4}{*}{ Direct } & Mood & $49(12.13)$ & $182(34.40)$ & $182(22.72)$ & $117(18.87)$ \\
& Performative & $8(1.98)$ & $0(0)$ & $1(.13)$ & $1(.16)$ \\
& Hedge & $10(2.47)$ & $4(.76)$ & $9(1.12)$ & $16(2.58)$ \\
& Obligation & $54(13.37)$ & $67(12.67)$ & $50(6.24)$ & $48(7.74)$ \\
& Want & $11(2.74)$ & $7(1.32)$ & $6(.75)$ & $7(1.13)$ \\
\hline \multirow{2}{*}{ onventionally indirect } & Suggestory & $6(1.49)$ & $0(0)$ & $0(0)$ & $0(0)$ \\
& preparatory & $\mathbf{2 2 7}(\mathbf{5 6 . 1 8})$ & $\mathbf{2 5 2 ( 4 7 . 6 3 )}$ & $\mathbf{5 2 9}(\mathbf{6 6 . 0 4})$ & $\mathbf{3 9 7}(\mathbf{6 4 . 0 3})$ \\
\hline \multirow{2}{*}{ Non-conventionally indirect } & Strong hint & $35(8.65)$ & $14(2.65)$ & $20(2.5)$ & $22(3.55)$ \\
& Mild hint & $4(.99)$ & $3(.57)$ & $4(.5)$ & $12(1.94)$ \\
\hline Total & & 404 & 529 & 801 & 620 \\
\hline
\end{tabular}


The percentages and the frequencies marked in bold indicate the most frequently-used strategy among the groups. As the table illustrates, both native English speakers and EFL learners tended to use conventionally indirect strategies. The results obtained showed that Query preparatory was employed most frequently to realize offering advice. The analysis of native speakers' data showed that, out of 404 giving advice speech acts identified in the data gathered, 227 offering advice (56.18\%) were realized through the Query preparatory strategy. Iranian EFL learners at low level of proficiency used 529 strategies among which 252 (47.63) were the Query preparatory of conventional indirectness strategies. In mid-level, they used 529 (66.04\%) query strategies and in high level, out of 620 offering advice speech acts identified, $397(64.03 \%)$ of them were query preparatory. The second most frequent strategy was direct strategy among both native English speakers and Iranian EFL learners. The native group tended to use obligation statements in 13.37 percent of cases, whereas Iranian EFL learners chose Mood strategies as the second most frequent strategy, registering $182(34.40 \%)$ cases for low proficient learners, 182 $(22.72 \%)$ cases for the mid proficient learners and 117 (18.87\%) instances for the high proficient learners.

The data indicated that the native speakers resorted to non-conventionally indirect, strong hints strategy, as their third preference. The analysis of native speakers' data showed that out of 404 giving advice speech acts identified in the collected data, 35 offering advice $(8.65 \%)$ were realized through the Strong Hints strategies. The Iranian low proficient learners used $14(2.65 \%)$ instance of strong hint, the mid proficient learners used $20(2.5 \%)$ cases, and the high proficient learners used $22(3.55 \%)$ cases of strong hints as their third preferred type of offering advice. There were few examples of the non-conventionally indirect mild hints offering advice strategies identified in data as reported in Table 1. And the least frequent strategies among the participants were respectively peformative and suggestory strategies.

As it was mentioned before, the other objective of this study was to investigate whether language transfer occurred while Iranian EFL learners realized offering advice acts. Both Iranian EFL learners (Low, Mid, and High English proficiency levels) and English native speakers demonstrated some slight similarities and noticeable variations in their offering advice samples. Three strategies of Query Preparatory (56.18\%), Mood Derivable (12.13\%) and obligatory (13.37\%) strategies, accounted as the most frequent offers, were produced by the native English speakers with. In general, English native speakers showed a tendency for indirect offering advice. However, the strategies Mood Derivable (34.40\%), Hedge (.76\%), Obligation (12.67\%), and Want $(1.32 \%)$ as Direct strategies of advice made up together some fifty percent of strategies, nominating direct strategies as the most frequently-used strategy used by Iranian lower level proficiency EFL Students.

The fact that Iranian at lower proficiency levels use direct type of offering advice more than high level proficiency learners can be accounted for by the notion of pragmatic transfer. Eslamirasekh (1993) reports that direct advice was the common form of offering advice speech act in the Persian language. Therefore, it is plausible to claim that the EFL learners in low proficiency group used this strategy more than the other groups as a result of pragmatic transfer. The notion of pragmatic transfer also holds true for the fewer use of non-conventional indirect strategies by low proficient Iranian EFL learners as compared with the other participants. Due to its grammatical complexity, the two non-conventional indirect strategies, namely strong hint and mild hint, which were frequently used by native speakers of English could not be automatized in Iranian EFL learners' inter-language at low proficiency level. Therefore, the learners in low proficiency levels resort to their first language pragmatic competence and transfer the knowledge in English context. This could lead to fewer uses of indirect strategies and more uses of direct advice strategies that are characteristics of native Persian speakers, as reported by Eslamirasekh (1993).

In order to find out whether there is a significant difference between the frequency use of offering advice strategies as realized by Iranian EFL learners (Low, Mid, and High English proficiency Levels) and those of native English speakers, the Chi-square analysis was applied. Table 2 displays the results.

Table 2. Chi-square value of offering advice by Iranian EFL learners and native speakers groups

\begin{tabular}{lll}
\hline$X^{2}$ & Df & Sig. \\
\hline 217.907 & 3 & .000 \\
\hline
\end{tabular}

$\mathrm{P}<0.05$.

Based on the result presented in Table 2, there is a significant difference in the frequency use of offering advice between Iranian EFL Learners (at different language proficiency levels) and native English speakers. The 
findings in the table displays that the difference is significant at $\mathrm{p} \leq 0.05$.

\section{Discussions and Conclusions}

Cross-cultural pragmatic and inter-language research studies have identified evidence that second language learners' pragmatic knowledge significantly affects their comprehension and production of pragmatic utterances in a second language (Kasper, 1992; Takahashi, 1996). The participants of the current study at low proficiency level transferred some norms of pragma-linguistic knowledge from Persian in the realization of offering advice. That is to say, compared to native English speakers who realized the speech acts of offering advice more indirectly, Iranian low proficient EFL learners performed their advice more directly. This is in line with Persian pragma-linguistic features as Eslamirasekh (1993) reports. In other words, to achieve offering advice goals, the low proficient learners in the present study may employ more familiar and easy forms of offering advice, which they have experienced in their native language. The higher proficient learners, on the other hand, were found not to transfer the Persian offering advice strategies and, therefore, used more indirect strategy types in their inter-language giving advice. It can be concluded that, based on the current study, language proficiency is positively associated with pragmatic transfer. The higher proficient learners showed greater awareness to the use of politeness strategies, namely directness, in offering advice as it was observed among native English speakers of the study.

To sum up, as results indicated the learners' proficiency levels affected the amount of advice speech acts realized by Iranian EFL learners. Moreover, the different percentage of advice strategies between Iranian EFL learners and native English speakers might have been because of the process of pragmatic transfer. Furthermore, the results revealed that perception of directness in the realization of offering advice speech act at earlier stages of EFL learning is influenced by Persian (L1) among Iranian EFL learners, though by the development of proficiency they apply more native-like perception of directness. However, the claims made in this study should be cautiously generalized since further studies are required in the EFL/ESL context to support the claims.

\section{Implications}

Cross-cultural communication is a must of our age. Therefore, cross-cultural studies in general and speech act studies in particular can shed further light on the nature of cross-cultural communication. The results obtained through studies like the current study could be of significance and practical uses for nonnative speakers to be more aware of the pros and cons of cross-cultural communications; the results highlights the acquisition of necessary communicative competence that enables nonnative speakers to perform a given speech act appropriately in a foreign speech community (Holmes, 1989; Yu, 2011). The results of the study are also applicable for foreign language teachers and learners. The former group should know how cross-cultural misunderstanding or offence in communication may occur due to lack of proficiency and knowledge of these devices. The results of this study also contributed to the growing research on inter-language pragmatics, and more specifically on pragmatic development of offering advice on the part of learners in EFL contexts. Given the low amount of cross-cultural studies on Iranian EFL learners' realization of speech acts, this study provided inter-language data on offering advice as well as pertinent baseline data from native speakers. More specifically, this study provided insights into Iranian language learners' awareness and performance of offering advice speech acts at different English proficiency levels. Language teachers need to integrate cross-cultural differences with their instruction syllabus for teaching offering advice speech act. Therefore, it is a prerequisite for the teachers to enhance their language learners' awareness of the differences between the perceptions of offering advice in their native culture and the target culture before instructing the advice formulae or expressions. As asserted by $\mathrm{Yu}$ (2004), besides grammatical language forms, learners need to pay attention to proper language use in order to achieve successful communication with the target language native speakers.

\section{References}

Austin, J. L. (1962). How to do things with words. Cambridge: Harvard University Press.

Bardovi-Harlig, K., \& Dornyei, Z. (1998). Do language learners recognize pragmatic violations? Pragmatic vs. grammatical awareness in instructed L2 learning. TESOL Quarterly, 32, 233-259. http://dx.doi.org/10.2307/3587583

Beebe, L. M., \& Takahashi, T. (1989). Do you have a bag? Social status and pattern variation in second language acquisition. In S. M. Gass, C. Madden, D. Preston, \& L. Selinker (Eds.), Variation in second language acquisition: Discourse and pragmatics (pp. 103-128). Clevedon: Multilingual Matters.

Blum-Kulka, S., House, J., \& Kasper, G. (1989). Investigating cross-cultural pragmatics: An introductory overview. In S. Blum-Kulka, J. House, \& G. Kasper (Eds.), Cross-cultural pragmatics: Requests and 
apologies (pp. 1-34). Norwood, NJ: Ablex.

Boxer, D. (1993). Complaints as positive strategies: What the learner needs to know. TESOL Quarterly, 27(2), 277-299. http://dx.doi.org/10.2307/3587147

Chang, Y. (2008). How to say no: An analysis of cross-cultural difference and pragmatic transfer. Language Sciences, 31(4), 477-493. http://dx.doi.org/10.1016/j.langsci.2008.01.002

Cohen, A. D., \& Olshtain, E. (1993). The production of speech acts by EFL learners. TESOL Quarterly, 27(1), 33-56. http://dx.doi.org/10.2307/3586950

DeCapua, A. (1998). Pragmatic transfer and cultural stereotyping. IAL (Issues in Applied Linguistics), 9(1), 21-36.

DeCapua, A., \& Wintergerst, A. (2004). Crossing Cultures in the Language Classroom. Ann Arbor, MI: University of Michigan Press.

Dörnyei, Z. (2007). Research methods in applied linguistics. Oxford: Oxford University Press.

Einsenstein, M., \& Bodman, J. W. (1993). Expressing gratitude in American English.

Ellis, R. (1984). Classroom second language development. Oxford: Pergamon.

Eslami-Rasekh, Z. (1993). A cross-cultural comparison of requestive speech act Realization patterns in Persian and American English. Pragmatics and Language Learning, 4, 85-103. Retrieved from http://eric.ed.gov/

Eslami-Rasekh, Z. (2004). Face-keeping strategies in reaction to complaints: English and Persian. Journal of Asian Pacific Communication, 14(1), 179-195. http://dx.doi.org/10.1075/japc.14.1.11esl

Fe'lix-Brasdefer, J. C., \& Ce'sar, B. (2004). Interlanguage refusals: Linguistic politeness and length of residence in the target community. Language Learning, 54(4), 587-653. http://dx.doi.org/10.1111/j.1467-9922.2004. 00281.x

Gass, S. N., \& Houck, N. (1999). Interlanguage refusals: A cross-cultural study of Japanese-English. New York:Mouton de Gruyter.

Ghawi, M. (1993). Pragmatic transfer in Arabic learners of English. El Two Talk, 1(1), 39-52.

Golato, A. (2002). German compliment responses. Journal of Pragmatics, 34(5), 547-571. http://dx.doi.org/10. 1016/S0378-2166(01)00040-6

Hassall, T. (2003). Requests by Australian learners of Indonasia. Journal of Pragmatics, 35, 1903-1928. http://dx.doi.org/10.1016/S0378-2166(03)00115-2

Hinkel, D. E., Wiersma, W., \& Jues, S. G. (1994). Applied Statistics for the behavioral sciences. Boston: Houghton Mifflin company.

Hinkel, E. (1997). Appropriateness of advice DCT and multiple choice data. Applied Linguistics, 18, 1-18. http://dx.doi.org/10.1093/applin/18.1.1

Hofstede, G., \& Bond, M. H. (1988). The Confucius connection: From cultural roots to economic growth. Organizational Dynamics, 16(4), 4-21.

Holmes, J. (1989). Sex differences and apologies: One aspect of communicative competence. Applied Linguistic, 10(2), 194-213.

Hymes, D. (1971). On communicative competence. Philadelphia, P. A.: University of Pennsylvania Press.

Kasper, G. (1992). Pragmatic transfer. Second Language Research, 8, 203-231.

Keshavarz, M. H., Eslami-Rasekh, Z., \& Ghahraman, V. (2006). Pragmatic transfer and Iranian EFL refusals: A cross-cultural perspective of Persian and English.

Koike, D. A. (1989). Pragmatic competence and adult L2 acquisition: Speech acts in interlanguage. Modern Language Journal, 73, 79-89.

Koike, D. A. (1996). Transfer of pragmatic competence and suggestions in Spanish foreign language learning. In S. Gass, \& J. Neu (Eds.), Speech Acts across Cultures: Challenges to Communication in a Second Language (pp. 257-281). Berlin/ New York: Mouton de Gruyter.

Kwon, J. (2004). Expressing refusals in Korean and in American English. Multilingua, 23(4), 339-364.

Liu, D. (1995). Sociocultural transfer and its effect on second language speakers' communication. International Journal of Intercultural Relations, 19(2), 253-265. 
Lwanga-Lumu, J. C. (2002). Internal request modification by first and second language speakers. Journal of Language Teaching, 36, 289-304.

Matsumura, S. (2001). Learning the rules for offering advice: A quantitative approach to second language socialization. Language Learning, 51(4), 635-679.

Nelson, G. L., Al-Batal, M., \& Echols, E. (1996). Arabic and English compliment responses: Potential for pragmatic failure. Applied Linguistics, 17(2), 411-432. http://dx.doi.org/10.1093/applin/17.4.411

Olshtain, E., \& Blum-Kulka, S. (1985). Degree of approximation: Non-native reactions to native speech act behavior. New York: Newbury House.

Olshtain, E., \& Cohen, A. (1991). Teaching speech act behavior to nonnative speakers. In M. Celce-Murcia (Ed.), Teaching English as a second or foreign language (pp. 156-165). Boston: Heinle and Heinle Publishers.

Qin, H. (2003). Pragmatic failures in interpreting business negotiation. Haerbin Gongye Daxue Xuebao (Shehui Kexue Ban). Journal of the Harbin Institute of Sociology (Social Sciences Edition), 5(2), 119-121.

Searle, J. R. (1975). Indirect speech acts. In P. Cole, \& J. Morgan (Eds.), Syntax and semantics (Vol. 3, Speech act, pp. 59-82). New York: Academic Press.

Shahrokhi, M. (2012). Perception of Dominance, Distance and Imposition in Persian Males' Request Speech ACT Strategies. Procedia - Social and Behavioral Sciences, 46, 678-685. http://dx.doi.org/10.1016/j.sbspro. 2012.05.181

Shahrokhi, M., \& Jan, J. M. (2012). The Realization of Apology Strategies among Persian Males. Procedia Social and Behavioral Sciences, 46, 692-700. http://dx.doi.org/10.1016/j.sbspro.2012.05.183

Takahashi, S., \& Dufon, M. (1989). Cross-linguistic influence in indirectness: The case of English Directive Performed by Native Japanes Speakers.

Tavakoli, A. A., Keenan, J. P., \& Crnjak-Karanovic, B. (2003). Culture and whistle blowing an empirical study of Croatian and United States managers utilizing Hofstede's cultural dimensions. Journal of Business Ethics, 43, 49-64.

Uso-Juan, E., \& Martinez-Flor, A. (2008). Teaching learners to appropriately mitigate requests. ELT Journal, 62(4), 349-357. http://dx.doi.org/10.1093/elt/ccm092

White, R. (1993). Saying please: Pragmalinguistic failure in English interaction. ELT Journal, 47(3), 193-202.

Wouk, F. (2006). The language of apologizing in Lombok, Indonesia. Journal of Pragmatics, 38, 1456-1486.

Yu, M. (2011). Learning how to read situations and know what is the right thing to say or do in an L2: A study of socio-cultural competence and language transfer. Journal of Pragmatics, 43(4), 1127-1147. http://dx.doi.org/10.1016/j.pragma.2009.09.025

\section{Copyrights}

Copyright for this article is retained by the author(s), with first publication rights granted to the journal.

This is an open-access article distributed under the terms and conditions of the Creative Commons Attribution license (http://creativecommons.org/licenses/by/3.0/). 